\title{
The Effects of Fluency Development Program on the Second Graders' Reading and Comprehension Skills
}

\author{
Aybala ÇAYIR ${ }^{1}$, Mustafa ULUSOY ${ }^{2}$
}

\section{Summary}

\section{INTRODUCTION}

Reading fluency is the ability to read accurately, quickly, effortlessly, and with appropriate expression and meaning (Rasinski, 2003). Reading fluency is characterized in the research as including rate, accuracy, and prosody. Reading fluency is important because it affects students' reading efficiency and comprehension. Fluency may be viewed as the bridge between basic word decoding and comprehension (Rasinski, 2003).

The National Reading Panel (2000) identified fluency as one of the five critical components of reading. Although fluency has been identified as a key element in successful reading programs, it is often not a significant part of them (Allington, 1983).

The purpose of this study is to investigate the effects of designed Fluency Development Program (FDP) on the second grade students' fluent reading and comprehension skills. To create the FDP, the literature related to fluent reading and reading comprehension was reviewed. The FDP is a flexible application which has been formed by examining all of the fluency programmes for improving the students' reading fluency and reading comprehension skills. Reading Fluency Development Programme (FDP) is an effective approach to teaching reading fluency that includes modeling, repeated reading, performance reading, assisted reading.

The FDP employs relatively short reading passages (poems, rhymes or other texts) that students read a brief period of time. The format for the FDP is:

1. The teacher introduces a new short text to the class and reads it aloud two or three times, while the students follow along silently. Modeling is an important component of instructing students for reading according to the cognitive strategies. Parents, peers and teachers must provide excellent models for students to hear effective reading.

2. The teacher and students discuss of the passage as well as the quality of the teacher's reading of the passage.

3. The teacher and students read the passage chorally.

4. The teacher organizes students into pairs. Each student practices the passage three times while his or her partner listens and provides support.

5. The following day students read the passage from the previous day to the teacher or a fellow student for fluency.

\section{METHOD}

The study designed as a "action research" of the qualitative research methods and conducted with 36 students who continue their education in the second grade of primary school in the province of Pursaklar in Ankara. Action research is an interactive inquiry process that balances problem solving actions implemented in a collaborative context with data-driven collaborative analysis or research to understand underlying causes enabling future predictions about personal and organizational change (Reason ve Bradbury, 2002).

\footnotetext{
${ }^{1}$ Ministry of National Education, aybalacayir@gmail.com

2 Assoc. Prof., Gazi University, Gazi Faculty of Education, mulusoy@gazi.edu.tr
} 
Cumhuriyet International Journal of Education-CIJE

e-ISSN: $2147-1606$

Vol 3 (2), 2014, $26-43$

\section{RESULTS}

At the end of the FDP process the students' reading errors are decreased and their prosodic reading level, reading speed and comprehension levels are increased. Furthermore, the use of the Reading Program provided opportunities for differentiated reading level achievement. Finally, the study revealed positive outcomes related to students's motivation, participation, and reading fluency. 